\title{
Propaganda protestante e imprentas en Barcelona \\ El colportor James Graydon y los impresos de Antonio Bergnes de las Casas (1835-1840)
}

\section{Doris Moreno \\ Universitat Autònoma de Barcelona | Doris.Moreno@uab.es / https://orcid.org/oooo-ooo3-2880-9533}

\author{
Pedro Rueda Ramírez \\ Universitat de Barcelona | pedrorueda@ub.edu / https://orcid.org/oooo-ooo1-5228-6774
}

\begin{abstract}
Resumen
Las sociedades bíblicas y misioneras comenzaron a distribuir Biblias y textos protestantes en España de manera regular a través de agentes en los años treinta del siglo XIX. En esta estrategia de distribución jugó un papel clave James Graydon. En Barcelona publicó el Nou Testament en catalán (1836) y la Biblia (1837) en español. Ambos fueron impresos en el taller de Antonio Bergnes de las Casas, además de otros impresos protestantes, de tono polémico y apologético, que el colportor distribuyó por toda la costa mediterránea. La red de agentes de Bergnes y el papel jugado por la publicidad en prensa fueron esenciales para la distribución de estos impresos protestantes, generando una importante respuesta católica en los diarios y en textos antiprotestantes, contribuyendo a profundizar el debate sobre la libertad religiosa y la libertad de cultos.
\end{abstract}

\section{Protestant propaganda and printing presses in Barcelona: the colporteur James Graydon and the prints of Antonio Bergnes de las Casas (1835-1840)}

\begin{abstract}
Biblical and missionary societies began to distribute Protestant Bibles and texts in Spain on a regular basis in the 1830 s, through agents. One of the most important of these agents was James Graydon. He operated in Barcelona, where he published the Nou Testament in Catalan (1836) and the Biblia (1837) in Spanish. Both works were printed at the workshop of Antonio Bergnes de las Casas, in addition to other polemic and apologetic Protestant, which the colporteur distributed throughout the Mediterranean coast. Bergnes' network of agents and the role played by press advertising were essential for the distribution of these Protestant works. They were met by a notable response from Catholics, in newspapers and in anti-Protestant texts, which deepened the debate on religious freedom and the freedom of worship.
\end{abstract}

Palabras clave

Protestantismo Libertad de cultos Tolerancia religiosa Imprentas Barcelona Siglo XIX

Keywords

Protestantism Freedom of worship Religious tolerance Printers

Barcelona

Nineteenth century 
1. Este trabajo se ha realizado en el marco del proyecto PGC2018-094899-B-C53, Herejía y sociedad en el Mundo Hispánico de la Edad Moderna: Inquisición, imagen y poder (2019-2021); y el proyecto

HAR2017-84335-P, Saberes conectados: redes de venta y circulación de impresos en España y Latinoamérica (2018-2021).

\section{Evangelización protestante internacional y libertad religiosa}

La uniformidad religiosa del Antiguo Régimen se prolongó en España en los inicios del siglo XIX con los paréntesis de 1812-1814 y 1820-1823. Sólo a partir de 1833 se introdujeron cambios significativos. La Inquisición española, que había sido abolida en tres ocasiones desde principios de siglo (1808 por Napoleón, 1813 en el marco de las Cortes de Cádiz y de nuevo en 1820 por Fernando VII), fue oficial y definitivamente suprimida en julio de 1834 (Martí Gilabert, 1975; La Parra y Casado, 2013). El programa liberal, con su estrategia de secularización, que implicaba la desamortización, se consolidó entre 1835 y 1843 , periodo durante el que la Iglesia perdió sus exacciones fiscales, sus tierras y propiedades (Nieto, 1996: 490-498). La consolidación del liberalismo propició una apertura religiosa tibia, más teórica que real, y siempre sujeta a las tensiones de geometría variable entre la Iglesia católica, las relaciones internacionales y los partidos en el poder (Bastian, 2001). ${ }^{1}$

Con todo, nunca se pretendió un distanciamiento del catolicismo. La confesionalidad española se plasmó en la constitución de 1812, el estatuto de 1834, el restablecimiento fugaz de la del 12 en la constitución de 1836 y en la de 1837. Todas las constituciones negaron la libertad de cultos. Sólo se permitió la práctica del culto privado no católico a los extranjeros. La uniformidad religiosa fue ampliamente tratada en los debates parlamentarios, pero finalmente resultaba un dogma político en el articulado constitucional.

Por otra parte, el catolicismo español se enfrentaba a los retos de los nuevos tiempos. Como escribió A. Moliner, frente al espíritu revolucionario y liberal de la primera mitad del siglo XIX la Iglesia católica impulsó la contrarrevolución y el ultramontanismo, condenando las corrientes de catolicismo liberal que se dieron en algunos países. El caso más emblemático fue el francés, con la condena papal del abad de Lamennais en la encíclica Mirari vos de agosto de 1832. En este texto, Gregorio XVI condenaba el liberalismo religioso o político señalando como errores la defensa de la libertad de conciencia, la libertad de prensa y el indiferentismo religioso (Bedera Bravo y Prado Moura, 2014; Moliner i Prada, 2016).

En España, la reacción de una parte significativa del catolicismo fue mirar al pasado, rescatar el orden antiguo, reivindicar la unión de la religión y la monarquía. La Iglesia católica española vio al liberalismo nacido en Cádiz como el responsable de una fractura social sobrevenida que no hizo más que pronunciarse después de la guerra de la independencia con el carlismo. No faltaron voces que intentaron conciliar la conciencia católica y el liberalismo, algunas tan señaladas como la de Jaume Balmes que trató de aportar las fibras necesarias para una modernización del pensamiento católico en el marco de la nueva cultura liberal (Fradera, 1996; Moliner i Prada, 2016). La confrontación entre estas dos formas de entender el catolicismo se profundizó a partir del Trienio Liberal, a la par que crecía el interés internacional por los sucesos de España, especialmente tras la llegada a Londres de exiliados políticos liberales que contribuyeron a incrementar las traducciones y fomentaron una visión crítica del papel de Fernando VII (Medina Calzada, 2019).

Los partidarios del trono y el altar veían en los cambios políticos y socioeconómicos que experimentaba el país, especialmente en las ciudades, una amenaza para la fe y la práctica cristiana, y un debilitamiento del poder de la Iglesia. Y como una cuña 
más, el protestantismo hacía acto de presencia, a juicio de algunos como disolvente de la unidad e identidad españolas (Alonso, 2014). Vicente de la Fuente valoraba las "críticas circunstancias en que se halla la nación española, expuesta a un cisma y a los ataques del Protestantismo que principia a invadir la península a cara descubierta" (Fuente, 1842: 3).

Aquel catolicismo liberal veía en la Biblia un instrumento de transformación no sólo religiosa sino también político-moral, la única vía posible de superar la superstición y la ignorancia y conectar el catolicismo renovado con la modernidad. No es extraño, entonces, que algunos de aquellos católicos liberales conectaran con las ideas y los hombres de la Sociedad Bíblica.

En la difusión de la Biblia a nivel mundial tuvo un papel fundamental la Sociedad Bíblica Británica y Extranjera (SBBE o BFBS, por sus siglas inglesas), creada en Londres en 1804 , y las múltiples sociedades bíblicas nacionales posteriores. El objetivo de las sociedades bíblicas era la difusión de la Biblia en lenguas vulgares, en formatos manejables y precios populares. Las Biblias debían estar totalmente exentas de comentarios y notas para garantizar la máxima libertad del ser humano ante el texto bíblico (Howsam, 2004). El personal de las sociedades bíblicas estaba formado por agentes o colportores cuya misión era difundir el texto bíblico, no crear comunidades. Tal como apunta Eaton "trabajaban bajo la falsa suposición de que, si pudieran distribuir suficientes copias del Nuevo Testamento y tratados religiosos, el público en general abrazaría su causa" (Eaton, 2015: xiv). Creían que la mera difusión del texto bíblico llevaría a una reforma personal, social y política que implícitamente implicaba la conversión al protestantismo.

En este marco descrito y en las páginas que siguen se abordará la reconstrucción de la labor de la SBBE en la costa mediterránea española a través de la actividad del irlandés James Graydon, atendiendo especialmente a la colaboración que le prestó el impresor y editor catalán Bergnes de las Casas, que puso a su servicio su red peninsular de libreros con los que mantenía intercambios. Analizaremos los textos que circularon, no sólo las Biblias en sus diferentes formatos y lenguas sino también folletos de carácter apologético. Estos impresos menudos, según los indicios, tuvieron una notable circulación, aunque apenas han sobrevivido en las bibliotecas y archivos españoles, configurando una especie de biblioteca evaporada que solo una paciente labor investigadora podría convertir en sólida. Finalmente, se esboza la respuesta que la sociedad española dio a esta circulación de biblias y folletos, una respuesta que fue desde la lectura, más o menos clandestina, a la condena más beligerante de una parte sustantiva de las elites eclesiásticas. A nivel político, las actividades de Graydon (y George Borrow en la parte occidental de la península ibérica) generaron un auténtico problema de Estado de nivel internacional. En el mundo del catolicismo más moderado, la presencia de los agentes de la SBBE estimuló la reflexión sobre temas clave en aquel contexto político: la tolerancia religiosa, la modernización de España o la propia identidad nacional.

Nuestras fuentes primarias para abordar todas estas cuestiones se han localizado en el Archivo Histórico Nacional de España (Madrid), el Arxiu Històric Municipal de Barcelona y la Biblioteca de Cataluña (Barcelona), el Archivo Diocesano de Barcelona, el Archivo Histórico Provincial de Cádiz, además de consultar la prensa contemporánea y las gacetas oficiales: El español, El Constitucional, La Verdad, Diario de Barcelona, Boletín Oficial de la Provincia de Málaga, Gaceta oficial de Valencia. También se han revisado las ediciones bíblicas barcelonesas y los folletos protestantes, estos últimos muy probablemente publicados en el taller de Bergnes de las Casas. 


\section{La lectura de la Biblia en vernáculo como instrumento de reforma. La Sociedad Bíblica Británica y Extranjera}

El artículo IV del Índice de libros prohibidos de 1564 prohibía la lectura de la Biblia en lenguas vulgares, una prohibición que asumió la Inquisición española. Sin embargo, durante el siglo XVIII algunos eruditos y eclesiásticos españoles defendieron la lectura de la Biblia en vulgar, en parte por la influencia del jansenismo francés. Esta idea fue extendiéndose a lo largo del siglo (Melchor, 2000).

Un cambio de actitud en Roma estimuló la opinión favorable a la traducción de la Biblia a las lenguas romances. En 1757 Benedicto XIV permitió estas traducciones siempre que fueran acompañadas de comentarios de autores católicos y aprobadas por la Sede apostólica. En España, a finales del XVIII, una nueva generación nacida de la reforma universitaria de Carlos III, el propio impulso interno hacia una reforma de la iglesia, y la influencia del jansenismo, había ampliado este debate. El Inquisidor General, Felipe Bertrán, discípulo de Gregorio Mayans, redactó un decreto conforme a las directrices de Benedicto XIV (1782) que fue incorporado como regla V en el Índice de libros prohibidos de 1790. Joaquín Lorenzo Villanueva, hombre de confianza del ya difunto Inquisidor General, publicó su defensa en De la lección de la Sagrada Escritura en lenguas vulgares (1791). El problema es que no había una traducción completa de la Biblia en castellano, realizada por autores católicos, disponible en el mercado del libro. A mediados del siglo XVIII, Mayans aconsejaba comprar una Biblia ReinaValera, la traducida por el protestante español Casiodoro de Reina, con los cambios añadidos de Cipriano de Valera, pero estos ejemplares no eran fáciles de conseguir (Mestre Sanchis, 2017: 152-153). En este contexto Carlos III encargó al padre Felipe Scío de San Miguel una traducción de la Biblia que, basada principalmente en la Vulgata, y con notas, se publicó entre 1790-1793.

Esta apertura hacia el texto bíblico se extendió por la península, dependiendo en buena medida del liderazgo de eclesiásticos de actitud más liberal. En Cataluña, los discípulos del obispo Climent (ob. 1766-1785) fueron los abanderados de estas reformas, el obispo Félix Amat y sus sobrinos Félix e Ignacio Torres Amat, con los que tuvo también amistad el obispo de Barcelona, Pedro Martínez San Martín (18321849), favorable a algunas de las tesis liberales y colaborador de los gabinetes de la regencia de María Cristina (Moliner i Prada, 2018:314-315). En este marco el canónigo liberal y filojansenista Félix Torres Amat publicó su traducción: La Sagrada Biblia, nuevamente traducida de la Vulgata al español (Madrid, Librería de Sánchez, 1823-1825, 10 vols.), basándose, al parecer muy ampliamente, en la traducción inédita que había hecho el jesuita José Miguel Petisco. Esta edición fue parcialmente costeada por la Sociedad Bíblica Británica y Extranjera (SBBE) y por la subscripción popular abierta por el pastor anglicano Andrew Cheaps entre sus feligreses ingleses. Esta traducción, con notas y comentarios, era superior a la del padre Scío aunque no más manejable para un lector sencillo. He aquí un buen ejemplo de la sintonía en este aspecto entre protestantes y católicos liberales. Una sintonía que no se extendió a las biblias sin notas, como demuestra el folleto de Félix Torres Amat, publicado en 1838 , en el que se oponía firmemente a estas biblias al modo protestante (Torres Amat, 1838).

En Cataluña no encontramos traducciones al catalán de biblias hasta muy tardíamente. En 1234 el rey Jaume I había prohibido la posesión y lectura del Antiguo Testamento y el Nuevo Testamento en romance. La primera Biblia impresa en catalán es la de Bonifaci Ferrer, impresa en Valencia (1478). Habrá que esperar al último tercio del siglo XIX para que haya un cambio significativo, con la notable excepción de un intento fallido en 1820-21 y Lo Nou Testament, publicado por la SBBE de Londres, en 1832 (Gili, 1943; Jardí, 1960; Biblia, 2008). Esta primera edición se publicó en casa de Samuel Bagster; y la segunda, también en Londres, en 1835 en la imprenta de Richard Watts. 
La SBBE muy pronto se interesó por España. Comenzó distribuyendo traducciones castellanas de la Vulgata, la del padre Scío y la de Torres Amat, aunque sin notas y in los libros considerados apócrifos por los protestantes. Eran traducciones de autores católicos con formato protestante. En 1808 regaló a todos los españoles prisioneros repatriados a España un Nuevo Testamento en la traducción del protestante español Francisco de Enzinas. En los primeros años, entre 1804-1814, tuvieron su mirada centrada en Europa y comenzaron su expansión en otros continentes, especialmente América, estableciendo puntos de distribución en Mallorca y Gibraltar, como lugar clave de distribución hacia el Atlántico español (Owen, 1817: 351; Jackson, 2004; Capó i Fuster, 2020: 94-96).

Algunos de los liberales españoles en Londres, en el periodo 1823-1833, se movieron en círculos de contacto con las sociedades bíblicas (Capó i Fuster, 1994). Es el caso de los catalanes Antoni de Puigblanch (que había publicado La Inquisición sin máscara) y Melcior Prat i Colom. Ambos participaban de la tertulia del pastor anglicano Irving y el reverendo Cheaps, amigo de Torres Amat, ambos relacionados con la SBBE. Asimismo, la SBBE tenía agentes y contactos en el sur de Francia que pronto mostraron interés por colaborar en la distribución de los textos bíblicos en Cataluña y el resto de España, como es el caso del pastor M. Lissignol en Montpellier, que mantuvo correspondencia con Félix Torres Amat. Estos contactos subrayan, una vez más, que el interés de la SBBE se fundamentó en una red de relaciones internacionales en las que participaban protestantes y católicos liberales españoles.

Los agentes de la SBBE fueron conocidos en España como colportores, una palabra que todavía hoy no aparece en el diccionario de la Real Academia de la Lengua Española. De origen francés, colporteur, vendedor ambulante, desde el siglo XIX en el protestantismo español el colportor era el vendedor ambulante de biblias. Podía además dar apoyo puntual a las familias o pequeñas comunidades que estuvieran interesadas en los pueblos y ciudades que visitaba, pero su objetivo no era permanecer en un lugar para establecer iglesias. La movilidad era su esencia. En contraposición, desde principios del siglo XIX se crearon sociedades misioneras cuyo objetivo era el establecimiento de iglesias, más o menos clandestinas. Los misioneros, además de biblias, distribuían con frecuencia folletos de tipo apologético y controversia doctrinal. En este sentido, las sociedades misioneras despertaron desde el primer momento una clara oposición y se situaron al margen del orden establecido en la medida en que no existía libertad de culto (Cobbett, 1850: 219-221).

\section{James Graydon en Barcelona}

En 1835 la SBBE envió a España dos agentes principales: George Borrow y James Graydon. Una tercera persona destaca como misionero por los mismos años: William H. Rule.

El caso de George Borrow (1803-1881) es, sin duda, uno de los más conocidos. Este aventurero inglés estuvo en Portugal y España entre 1835 y 1840. En su conocida obra La Biblia en España (1843) contaba la historia de sus viajes por España como agente de la SBBE. El libro fue traducido al español por Manuel Azaña, primero con un adelanto en revistas, en 1920, y en una edición en forma de libro en 1921. Esta versión de Azaña ha tenido notable éxito y ha dado a conocer a Borrow al público español. La narración de sus peripecias le dio en Inglaterra una notable fama (Collie, 1982). El relato de sus viajes desgranaba un sinfín de contactos con libreros y lectores españoles, en un contexto poco favorable para la distribución de libros protestantes. El pastor y misionero William Harris Rule (1802-1890), por su parte, se instaló en Gibraltar en 1832, nombrado por la Sociedad Metodista Misionera de Londres. Escritor prolífico 
2. The National Archives. ADM 196/4/296. Lieutenant James Graydon, Date of Appointment: 21 March 1814. http://discovery. nationalarchives.gov.uk/details/r/ C9705899. También en $A$ List of the Officers of the Army and of the Corps of Royal Marines, on Full, Retired, and Half Pay. Londres, 1835 , p. 430. en un buen castellano, distribuyó sus libros y folletos por las costas andaluzas, bien directamente o a través de agentes y en depósito con libreros, contando con el apoyo de la SBBE (Zaro, 2015). Rule también narró sus aventuras y defendió su labor en sus Memoir of a Mission to Gibraltar and Spain (1844) y las Recollections of My Life and Work at Home and Abroad (1886) (Zazo Esteban, 2015:343-344). Para J. B. Vilar, Rule es "junto con Borrow, la personalidad señera del protestantismo insular entre cuantos se relacionaron con la Península Ibérica en el siglo XIX" (Vilar Ramírez, 1994: 141142) (Figura 1).

La tercera personalidad destacada de estos años fue James Graydon, anglicano irlandés y teniente de la Armada británica en la reserva desde 1815, lo que le permitió viajar con el tiempo y los medios suficientes. ${ }^{2}$ Se ofreció a colaborar con la SBBE. Si Borrow desarrolló su labor en el centro y suroeste de la Península, Graydon se proyectó sobre el este peninsular, viajando por las poblaciones costeras desde Barcelona a Málaga. El primer historiador de la SBBE, George Browne destacaba su papel como

"un devoto amigo de la Sociedad... un caballero que había residido durante algunos años en Suiza, y anteriormente un agente activo en la distribución de las Escrituras en España..." (Browne, 1859: I, 475).

Graydon eligió Barcelona como plataforma desde la que desarrollar su labor como agente de la SBBE. A su llegada en 1835 encontró una ciudad y una Cataluña convulsas. Ese año fue asesinado el capitán general Bassa en el marco de las bullangas, los tumultos populares, la quema de conventos, la persecución del clero, que se sucedieron en los años siguientes, con numerosas corrientes de fondo del liberalismo de corte radical y oposición al absolutismo tras la muerte de Fernando VII (Roca Vernet, 2011; Ghanime Rodríguez y Cao Costoya, 2013: 34-36). Las algaradas de las milicias en Barcelona en 1837 provocaron una de las varias crisis políticas de la década (Roca Vernet y Miquel Magrinyà, 2021). Las muestras de anticlericalismo y anticatolicismo se multiplicaron en aquellos años en una ciudad en la que las fábricas, especialmente las textiles, los mercados y la participación política estaba transformando la vida cotidiana (Moliner i Prada, 2018: 307-308). Los cambios y transformaciones del proceso de industrialización y urbanización tensionaban la ciudad (Fradera, 2002). Un incipiente movimiento republicano se intensificó a lo largo de la década de los 30, organizado en sociedades secretas y entre 1836 y 1837 publicaba el periódico El Sancho Gobernador, y más tarde El Popular, con artículos profundamente anticlericales $\mathrm{y}$, al mismo tiempo, defensores de una religión cristiana más sincera y tolerante, abierta a la razón y al mundo moderno, que identificaban con el protestantismo (Barnosell, 2012).

Varias fueron las razones que pudieron determinar la elección de Graydon y la SBBE: los contactos que mantuvo con el pastor Lissignol en Montpellier, que había impulsado a la altura de 1820 una publicación del Nuevo Testamento en catalán que no llegó a prosperar; la existencia de una comunidad protestante en la ciudad, integrada por ciudadanos de otros países, que en 1835 disponían de un cementerio anexo al de la ciudad gestionado por los cónsules extranjeros; y el activismo de grupos de exiliados retornados que, en privado, se mostraban favorables a la tolerancia religiosa y a finales de la década de los 30 explicitaban sus ideas en la prensa periódica liberal como El Museo de Familias, El Popular o El Constitucional (Roca Vernet, 2018). Estos círculos mantenían contactos continuados con Inglaterra, por estudios, política o, sencillamente relaciones de amistad (Santiño, 2018: 255-257). Los protestantes extranjeros radicados en Barcelona practicaban su fe en privado en Barcelona, amparados por los convenios internacionales y ciertos sectores intelectuales y políticos de la ciudad se abrían a un debate sobre la tolerancia religiosa. 


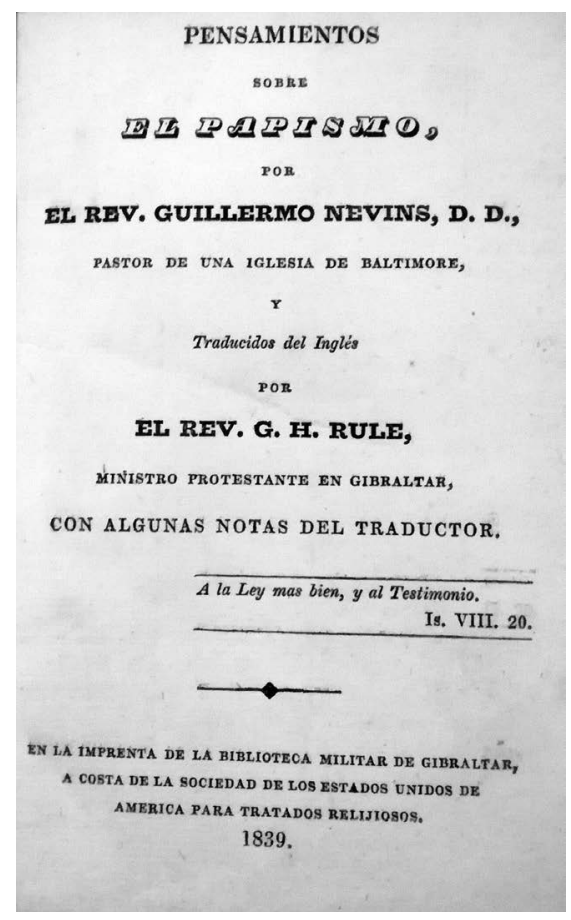

Figura 1. G. H. Rule. Pensamientos sobre el papismo. Gibraltar, 1839. Fuente: Biblioteca de la Catedral del Redentor (Madrid).

Graydon debió conocer y frecuentar estos círculos. Con certeza tuvo relación con uno de los personajes más interesantes: el filósofo y helenista Antonio Bergnes de las Casas (1801-1879), que llegaría a ocupar el cargo de concejal en el ayuntamiento, en 1835 , mientras dirigía su editorial, muy activa entre 1830 y 1843 . Sus inquietudes intelectuales, científicas y espirituales son bien conocidas (Olives Canals, 1947; Camós, 2020). Bergnes, por ejemplo, fue el introductor del evolucionismo en España, editando a Buffon, Lamarck y otros, y tradujo a Goethe, Chateaubriand y Walter Scott, de quien fue amigo personal (Camós, 1998). Fuertes indicios señalan su adhesión a los cuáqueros, a quienes habría conocido en un viaje a Londres. Desde 1818, y de manera esporádica, algunos miembros de la Sociedad de los Amigos habían pasado por Barcelona contactando con él. Precisamente el cuáquero William Allen, fundador de la Sociedad para la difusión del conocimiento útil en Londres, visitó Barcelona en 1833 para conocer al obispo Torres Amat participando Bergnes de los encuentros y debates que se abrieron en casas particulares (Caballer Albareda, 2020: 85-87). Su papel como editor, pero también su dominio del inglés y el francés y las relaciones con la élite barcelonesa, le permitieron actuar como mediador y enlace en muchas iniciativas (Camós, 2013). Son numerosas las impresiones y traducciones que hizo de autores e ideas protestantes (Olives Canals, 1947: 192). El taller se encontraba en una zona de expansión de la burguesía comercial, en la calle Escudellers en la que podían encontrarse viviendas señoriales y talleres de artesanos, cerca de la fonda "de las cuatro partes del mundo" desde la que distribuía Graydon los ejemplares de la Biblia (Romea Castro, 2016: 310-311) (Figura 2).

En el momento de llegada de Graydon el impresor había solicitado al Ayuntamiento, el 22 de mayo de 1835, un cambio del rótulo de su establecimiento, que decía "Imprenta de Don Antonio Bergnes y Compañía", pero quería modificarlo por el de "Imprenta y Librería de Don Antonio Bergnes", como explica en su petición "por haberse dividido aquella sociedad, y seguir el establecimiento por su propia cuenta". ${ }^{3}$ En este caso se trataba de la separación de su socio Manuel Rivadeneyra (1805-1872) con el 
Figura 2. Dibujo del rótulo de la librería de Antonio Bergnes de las Casas. AHMB. Urbanisme i obres. Llicències obreria 1.CXIV-121/1835.

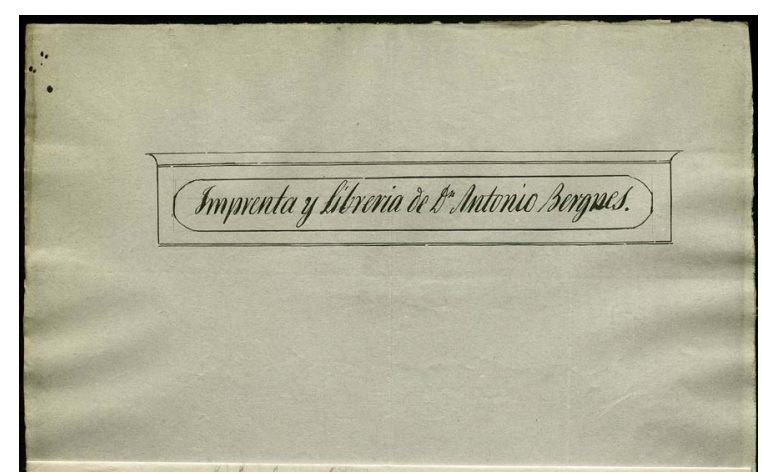

que Bergnes mantuvo el negocio durante cuatro años. En 1835 disolvieron la sociedad amistosamente, iniciando Rivadeneyra una nueva razón social como "Imprenta de M. Rivadeneyra y Cia". Este impresor y editor finalmente se establecería en Madrid publicando la conocida Biblioteca de Autores Españoles (1846-1880) (Botrel, 2008).

En el momento de la impresión de los textos bíblicos el impresor tenía el control de su negocio, y actuaba con plena autonomía en sus decisiones editoriales, una libertad con la que diseñó por un lado proyectos en atención a la rentabilidad económica de su empresa editorial, y, por otro lado, estrategias intelectuales que singularizaran su taller en un mercado crecientemente competitivo. Este fue otro de los factores de su éxito. Su apoyo a la edición de la Biblia y, quizá, folletos protestantes, no fue sólo una decisión empresarial sino también ideológica. El filocuáquero Bergnes creía que el acceso a la Biblia traía libertad a las personas y las sociedades y por ello se identificaba con la labor de la SBBE. Así lo exponía en una carta a la SBBE de 1837:

Toda la gente honesta verdaderamente liberal estaría encantada de ver la religión reformada y fundada sobre la Palabra de Dios, y no, como ocurre en España, sobre las ficciones y perversas alucinaciones de Roma, fuente de todos nuestros infortunios. La Extensión de las Sagradas Escrituras está preparando el camino para ese deseado momento y si el partido carlista es vencido, yo espero que no esté lejos el día cuando la Sociedad Bíblica recogerá los frutos de su celo y esfuerzo en favor de mis compatriotas (Barrass, 1968: 309, traducción de los autores).

Aunque con precedentes anteriores que no prosperaron, la llegada de agentes ingleses abrió el camino para convertir a España en el primer eslabón de difusión de textos bíblicos en aquellos años para el mundo hispano y el sur de Europa (Thomson, 1853: 17-19; Capó i Fuster, 2020: 97-102). Graydon llegó con el encargo de difundir la Biblia en castellano y en catalán a partir de las ediciones de Londres. Los destinatarios eran los lectores de los territorios del Mediterráneo, desde el sur de Francia hasta Málaga. La clave era cómo introducirlos en España y distribuirlos sin suficientes agentes sobre el terreno, formando parte de una estrategia global para el Sur de Europa (Jackson, 2004).

Un paso más debía ser conseguir la preceptiva autorización para publicar en España. Esto resultaba complejo, la legislación de Fernando VII fue restrictiva, como la Real Orden de 12 de julio de 1830 que establecía la prohibición de todo libro "o papel grande o pequeño, que sea contra nuestra santa y única Religión Católica” (Eguizábal, 1879: 165). Tras la muerte del rey se inició un periodo de regencia en el que los gobiernos procuraron sortear las restricciones con una mayor apertura y un nuevo reglamento que restaba trabas a la publicación, especialmente para la prensa periódica (Eguizábal, 1879: 177-178). En los primeros meses de 1836 tanto Borrow como Graydon afirmaban haber conseguido una autorización verbal del primer ministro Mendizábal primero 
e Isturiz después para la impresión del Nuevo Testamento, siempre en las versiones de Scío y Torres Amat, aunque probablemente no explicitaron que eran sin notas (Giménez Cruz, 1987: 228-230). Este paso fue esencial para desarrollar la estrategia de publicación de la Biblia en territorio español.

En el caso de Lo Nou Testament, los contactos con el editor Bergnes de las Casas permitieron una nueva edición, en 1836, con el título de Lo Nou Testament de Nostre Senyor Jesuchrist traduhit de la Vulgata llatina en Llengua Catalana, ab presència del text original en la traducción de Prat i Colom. El 19 de octubre de 1835 una carta de Graydon a la SBBE informaba del perfil social y político de Bergnes, recién elegido para el cabildo municipal, consideraba que el editor "goza de una alta reputación", y anunciaba que estaba negociando el presupuesto para imprimir con él la Biblia. (Barrass, 1968: 267). El 10 de diciembre de 1835 comunicaba el estado del proyecto, indicando que "el último lunes firmé un contrato con el librero Bergnes para una edición en $8^{\circ}$ [...] del Nuevo Testamento en catalán" (Barrass, 1968: 274). La edición, que sería de 3000 ejemplares vio la luz unos meses más tarde y comenzó a repartirse en la ciudad. El pie de la obra indicaba claramente la financiación londinense del libro, ya que fue "Imprés per la Societat Inglesa y Estrangera de la Biblia, en la estampa de Anton Bergnes". Esta edición imitaba la de 1832, incluso la composición en página de ambas portadas es idéntica, con la misma estructura, uso de filetes y cursivas. La similitud entre las ediciones es interesante, y sin duda fue deliberada. Curiosamente, esta edición de 1836 volvería a publicarse sin dar noticias de la participación de Prat i Colom como traductor. A finales de 1837 explicaba en sus informes que del Lo Nou Testament quedaban 723 en el depósito, 1739 habían sido vendidos y 105 regalados en Barcelona, y 197 habían sido enviados a diversas personas (Barrass, 1968: 296).

La impresión de Lo Nou Testament no tuvo problemas. Sospechamos que, en parte, gracias a que, en aquel momento, y desde 1835, el gobernador de Barcelona era precisamente Josep Melcior Prat i Colom, que había regresado del exilio en 1833. Prat entró de nuevo en la política, aunque silenciando su colaboración con la SBBE londinense (Llorens, 1968: 160-162). El peso como liberal exiliado y su papel conciliador entre las diferentes corrientes liberales fue esencial para promocionar de secretario de gobernación a gobernador. Sus inquietudes culturales y afinidades políticas lo situaron en el círculo de Bergnes. Entre otras iniciativas destacadas, Prat restableció la Academia de Bones Lletres de Barcelona y propuso que Bergnes se incorporase como miembro de número, inaugurando una carrera académica que también le llevaría a la universidad de Barcelona. No parece descabellado, a pesar del silencio de las fuentes, considerar la existencia de contactos entre Graydon y Prat i Colom a través de Bergnes.

Tanto Graydon como Bergnes informaron a la SBBE del éxito de venta de los textos bíblicos. El editor Bergnes de las Casas informaba del éxito del Nuevo Testamento en catalán entre las clases más populares de la ciudad y de la reacción solapada de un clero que no se sentía suficientemente seguro de su influencia para lanzar una ofensiva abierta en un contexto especialmente conflictivo (Barrass, 1968: 307-310). Este éxito le llevó a considerar la apertura de una capilla protestante. Según Graydon, había algunos barceloneses que se habían interesado en su iniciativa. Como afirma Barrass, no se puede saber cuántos apoyos tenía para su propuesta. De hecho, reconocía en su correspondencia no tener cualidades para la predicación, por lo que le pidió a William Rule, que tenía probada capacidad y experiencia en ello, que pensara en trasladarse a Barcelona donde contaban con el apoyo del cónsul inglés en la ciudad. Pero en el contexto de las bullangas iniciadas en 1835 antes mencionadas, con algaradas en las calles y reacciones contra los revoltosos y deportaciones entre los grupos de liberales progresistas que participaron, una tarea misionera como la que proponía Graydon podía encontrarse con numerosos problemas en una ciudad 
Figura 3. Portada de La Biblia, ò el Antiguo y Nuevo Testamento. Barcelona: En la Imprenta de A. Bergnes, 1837. Biblioteca de Cataluña, A 22-8-169.

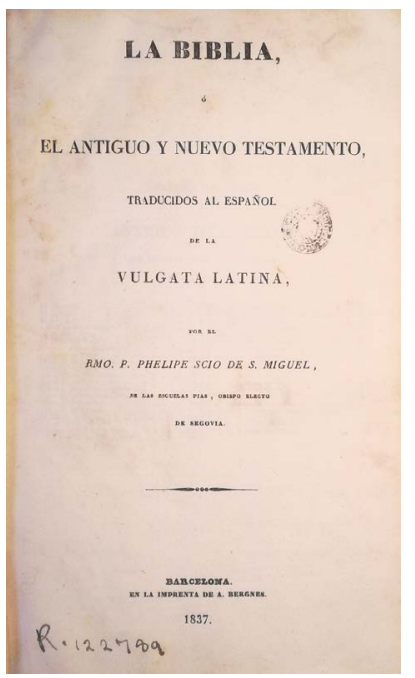

preocupada por el "asedio" carlista y las guerras internas de los liberales (Janué i Miret, 2004). El proyecto no prosperó.

Bergnes también editó por encargo de Graydon una Biblia en castellano (1837) (Figura 3) que contaba con una estructura claramente diferenciada para el Antiguo Testamento ([6], 786 p.) y el Nuevo Testamento ([4], 252 p.), con portadas distintas y signaturas para cada parte. Esta estructura permitía la venta completa de la Biblia, o separar El Nuevo Testamento. En este caso se eliminaron las referencias del pie de imprenta a la "Societat Inglesa y Extrangera de la Biblia" que habían aparecido en la edición en catalán de Lo Nou Testament. En la portada se dejaba claro que era la edición del obispo de Segovia, Felipe Scío de San Miguel. Como dato curioso, la Sociedad Bíblica insistió en que primero se imprimiese el Nuevo Testamento, aunque los agentes de la sociedad en España afirmaban que los españoles preferían la Biblia completa y no sólo el Nuevo Testamento.

\section{El itinerario de Graydon desde Barcelona hasta Málaga}

4. Diario de Barcelona, 5 de enero de 1837, p. 40.
Entre julio de 1836 y abril de 1837 Graydon actuó desde Barcelona, en una fonda de la calle de Monserrat en el número 14, una de las áreas urbanas más dinámicas, y en expansión demográfica, situada en la zona del Raval y bien conectada con zonas altamente pobladas e industrias textiles (Garcia i Espuche y Guàrdia i Bassols, 1986: 85). En esta fonda vendía Lo Nou testament a 10 reales y ofrecía "gratis juntamente con cada ejemplar del Nuevo Testamento que se vende, otro de una obrita para facilitar el estudio de la Sagrada Escritura", ${ }^{4}$ un folleto probablemente de carácter apologéti$\mathrm{co}$, que permitía hacer proselitismo protestante. No hemos podido confirmar si estos folletos salieron de la prensa de Bergnes o fueron importados.

Importar las biblias y textos protestantes de Inglaterra suponía un problema logístico y legal. En el momento de entrada en las aduanas se corría el riesgo de dilaciones y posibles delaciones (Vilar Ramírez, 2008). En este terreno los cónsules ingleses eran esenciales para negociar con las autoridades locales y facilitar la salida de los almacenes. Las cartas enviadas por Luis Usoz a su corresponsal en Inglaterra revelan las dificultades del tráfico de libros protestantes, que le hacían desconfiar de las aduanas, recomendando que los libreros londinenses con los que trabajaba le enviasen los libros de su interés "a la Embajada inglesa en Madrid" que servía de puente para hacer 
llegar a Usoz libros prohibidos que luego editó en su colección de autores reformados (Vilar Ramírez y Vilar García, 2010: 134).

Las actividades de Graydon despertaron la atención de la prensa, que clamaba el 6 de septiembre de 1836 que "la sociedad bíblica de Londres ha establecido en Barcelona un depósito de sus biblias, traducidas con tanta ignorancia como mala fe, y de las que se dan también ejemplares gratuitamente en idioma francés en Tolosa". ${ }^{5} \mathrm{El}$ papel de Toulouse, y en general del sur francés, en la distribución de biblias queda reflejado en este comentario. La distribución de estos textos se consideraba "una invasión del protestantismo". La impresión de Lo Nou testament $(1832,1835,1836)$ y del texto completo de la Biblia en castellano (1837) permitió contar con un fondo editorial notable para su redistribución. La fonda actuaba como depósito para guardar y vender los ejemplares e iniciar los viajes de reparto. En Madrid George Borrow contaba con un local propio para el despacho de biblias y, además de anunciarlo en la prensa, imprimió "tres mil carteles en papel amarillo, azul y carmesí, y los pegué por las esquinas" (Borrow, 1970: 411). Esta estrategia le dio notable resultado y la repitió en los lugares que visitó en Castilla. También Graydon utilizó los carteles en sus viajes por el área mediterránea, como los que remitió a Cartagena para fijar en las calles (Barrass, 1968: 325).

En los años de 1836, 1837 y 1838 Graydon viajó a Valencia, Alicante, Murcia, Cartagena, Almería y Málaga. También hizo breves viajes a Francia y quizá a Inglaterra. Remitió en rama ejemplares a Borrow, que se encargó de su distribución desde Madrid a través de sus propias redes (Vilar Ramírez, 1994: 75). Al abandonar las ciudades visitadas dejaba ejemplares de la Biblia en fondas y casas de libreros para su venta. Los mecanismos de publicidad y venta más habituales fueron los carteles, ya mencionados, y los anuncios en la prensa.

Los ejemplares de la Biblia impresos por Bergnes permitieron a Graydon iniciar la actividad, anunciando la venta en el Diario de Barcelona el 17 de abril de 1837:

En obsequio a la clase útil y laboriosa, que, en medio de las actuales circunstancias está padeciendo las escaseces consiguientes a la guerra fratricida que hacen a la libertad y a las luces la ignorancia y el fanatismo, el encargado por la sociedad Bíblica Británica y extranjera en Londres ha resuelto vender el Nuevo Testamento en idioma catalán, impreso en esta ciudad y en pasta, al ínfimo precio de 5 reales de vellón a cuantos al efecto se presenten en la librería del mismo encargado A. Bergnes, calle de Escudellers, núm. 36 (Barrass, 1968).

La guerra fratricida era la carlinada. Unas semanas más tarde, un nuevo anuncio prorrogaba la oferta hablando del éxito de ventas. En agosto de 1837 Bergnes afirmaba que el clero de Barcelona no se oponía abiertamente a la circulación de la Biblia, pero sí había iniciado una campaña de descrédito que, contrariamente a sus deseos, estaba estimulando la curiosidad de los barceloneses (Barrass, 1968: 304).

El 30 de junio de 1837 Graydon publicó en el Diario Mercantil de Valencia un anuncio en el que informaba de la venta a precio módico, e incluso donación, de la Biblia presentada como una edición fiel al original, no alterada "por decisiones de los hombres sujetos al error". El anuncio incluía una polémica frase: "ya era hora que se despoje a la religión cristiana de la superstición y el fanatismo, para que sólo permanezca la moral acendrada del evangelio" y vinculaba la lectura de la Biblia a la conquista de la libertad. En Valencia logró vender 302 copias y donar 68, contando con la ayuda del sacerdote parroquial Pascual Marín (Barrass, 1968: 319-320). Pero a mediados de agosto tuvo que abandonar la ciudad por la oposición abierta del arzobispo que publicó una carta pastoral prohibiendo la venta de Biblias londinenses en
5. Gaceta Oficial, núm. 91,6 de septiembre de 1836, p. 464 . 
6. El Español, 5 de noviembre de 1837, p. 3.

7. Boletín Oficial literatio, industrial y
mercantil de la Provincia de Málaga, 24 de abril de 1838, núm. 1416.

8. Archivo Histórico Nacional (AHN), Inquisición, leg. 11320, n. 43.

9. AHN. Estado, leg. 5502, exp. 59. su sede, el 4 de julio de 1837, y más tarde un artículo muy duro contra sus actividades, subrayando la existencia de apoyos locales a través de una comisión encargada de la venta y distribución de las biblias aportadas por el irlandés. ${ }^{6}$

Entre septiembre y principios de noviembre de 1837, Graydon fue a Alicante donde vendió 296 ejemplares, y desde allí a Gibraltar y a Almería; desde esta ciudad volvió a Cartagena y Murcia llegando de nuevo a Barcelona en enero de 1838 (Barrass, 1968: 321-323). Graydon constató que en aquellos meses de otoño el clima político había cambiado. Tras la aprobación de la constitución de 1837 los moderados habían ganado las elecciones y las restricciones a su trabajo aumentaron.

En 1838 Graydon continuó visitando los depósitos y libreros de su, ahora, extensa red. El 26 de abril de 1838 publicó en el Boletín de la Provincia de Málaga el anuncio de la venta de biblias, pero su artículo incluía algunas frases que incendiaron al clero catedralicio y provocaron la reacción del obispo. En el texto destacaba que:

Con todas sus veras el encargado llamaría la más grande atención de cada miembro de la gran familia Española a este libro DIVINO, para que POR ELLA se entere de la causa principal, si no la UNICA de todas sus terribles aflicciones, y de su ÚNICO remedio, como está tan claramente manifestado en la sagrada Escritura. Un abominable sistema de superstición y fanatismo, VORAZ ÚNICAMENTE de PESETAS, y no de la felicidad temporal NI ETERNA de los hombres ha prevalecido en España (como también en otras naciones) durante larguísimos siglos, por la exclusión ABSOLUTA del verdadero conocimiento del gran Dios y juez final de todos los hombres; y así la ha abismado de calamidades las más espantables.7

El texto conectaba bien con el arraigado anticlericalismo tradicional que clamaba contra la superstición, el fanatismo y la avaricia de la Iglesia.

La distribución de biblias se sustentaba en la red de contactos y relaciones que tanto Borrow como Graydon, cultivaron, buscando la colaboración de libreros locales. Esta estrategia permitía contar con agentes que iban distribuyendo al por menor ejemplares. Desde Murcia el 21 de julio de 1838 se informaba al Secretario de Estado de que "Don Sebastián Hernández impresor en esta capital ha vendido cuarenta y siete ejemplares que al efecto le entregó Mr. Jayme Graidon, súbdito inglés a su salida de ella". ${ }^{8}$ En Alicante volvemos a encontrarnos una red de distribución dejada a su paso. En la fonda o café del león un sirviente, Miguel Cortés, vendía "diferentes tomos que dejó a su cargo cierta persona cuyo nombre y apellido ignora, pero que era inglés".?

\section{Los impresos de polémica religiosa}

La oposición que los agentes ingleses despertaron fue desigual, aunque el resultado final fue el mismo. La clave está en la perspectiva con la que ambos abordaron su tarea. Uno de los aspectos que interesaron a Graydon fue promover un debate que le permitiera granjearse el favor de algunos partidarios de la libertad de cultos. Sus anuncios de prensa, en ese sentido, parecen radicalizarse a medida que avanzaba por el territorio. El factor definitivo fue, quizá, la distribución gratuita de trataditos impresos, al menos tres de ellos de 1836 y uno de 1837 , sin pie de imprenta entre el público interesado. Estos folletos le granjearon serios problemas, ya que aunaban proselitismo protestante y críticas a la Iglesia Católica.

Ya hemos mencionado que en Barcelona Graydon vendía biblias y nuevos testamentos ofreciendo gratuitamente un folleto que, según él afirmaba en la publicidad en prensa, podía ayudar a comprender mejor la Biblia. No sabemos nada de su contenido. 
Posteriormente, en Murcia, Cartagena y Alicante distribuyó otros folletos. En 1838 Francisco Castelar, celador de protección y seguridad pública, reconocía en una fonda alicantina un lote de impresos que había dejado un "inglés" a cargo de un sirviente, y que quedaron descritos y confiscados:

Treinta y tres folletos titulados, autoridad, objeto y efectos del cristianismo, segunda edición. Diez ídem, titulados Catolicismo primitivo. Trece ídem, titulados, catecismo sobre las principales controversias de los protestantes con los católicos. Y dos ídem, pequeños, titulados, Historia verdadera de la virgen dolorosa. ${ }^{10}$

Estos cuatro impresos eran los mismos que recibió el impresor (y librero) Sebastián Hernández en Murcia, remitidos desde Barcelona por la vía de Cartagena por Bergnes de las Casas en marzo de 1838. Es clara la continuidad de la propaganda, utilizando las redes tejidas por Graydon y la estrecha colaboración del editor Bergnes en la configuración de la red de agentes de venta. El papel de Bergnes como editor de libros, pero también periódicos de amplia repercusión como El Museo de las Familias, le permitieron construir esa red de distribución en las principales ciudades españolas (Thion Soriano-Molla, 2013). En la carta remitida por él desde Barcelona que acompañaba el lote se informaba de que se enviaban, por orden de Graydon, 1000 ejemplares de la Carta a un amigo, otros 1000 de El Catolicismo primitivo, 500 de Catecismo sobre las principales controversias de los protestantes y 500 de la Historia verdadera de la Virgen Dolorosa. Los 3.000 ejemplares se vendían, a uno o dos reales. Las autoridades interceptaron 2.430 folletos. El papel de Bergnes fue más allá de la distribución ya que algunos elementos de los impresos, como la tipografía gótica empleada en las portadas, fueron habituales en su taller, revelando que además de distribuirlos fueron, como parece lo más probable, impresos en su imprenta. La red de intermediarios, en estos casos, la explica Borrow, que comenta el notable papel de muleteros, carreteros, contrabandistas y arrieros, que llevaban generalmente de avanzada lotes a las ciudades que visitaba (Borrow, 1970: 407-408). En el caso de Graydon debió emplear medios similares, además de la vía marítima, con la ayuda de Bergnes de las Casas y su red de compra-venta y suscripción, que permitían saber de antemano qué libreros debía visitar para negociar las ventas y acordar la publicación de los anuncios en los diarios locales.

El primero de los impresos investigado en Murcia fue la Carta a un amigo sobre la autoridad, objeto y efectos del Cristianismo, y en especial sobre la doctrina de la redención por José Juan Gurney, y traducido al español por J. L. Villanueva, tercera edición, 1836. Joseph John Gurney (1788-1847) fue un ministro cuáquero antiesclavista bien conocido por Bergnes; y el traductor, Joaquín Lorenzo Villanueva, ha sido valorado por Moliner (2016) como el primer representante del catolicismo liberal al defender la compatibilidad entre el liberalismo político y el catolicismo. Villanueva era un viejo conocido de la SBBE. La elección de este folleto para su distribución parece encajar con el interés de Graydon en conectar con las corrientes liberales y atraer un público favorable a la recepción de estas tendencias, partidarias de suavizar la retórica contra la libertad de cultos. En este caso se trataba de un folleto de 56 páginas a línea tirada y una reveladora ausencia del taller de impresión.

El segundo impreso retenido por las autoridades el 12 de mayo de 1838 fue El Catolicismo primitivo, por el Rdo. Juan Gossner, clérigo católico de Munich. Traducido del francés. Tercera edición. 1836. Otro pequeño impreso sin pie de imprenta y sin indicación del nombre del traductor. El título era suculento porque, efectivamente, el alemán Joahn Gossner había sido sacerdote católico, pero se había pasado al protestantismo en 1826.

El tercero fue el Catecismo sobre las principales controversias de los protestantes con los católicos. Traducido al español. 1836. Este era un impreso vendido a dos reales. La
10. AHN. Estado 5502, exp. 59. Los problemas y embargos en las aduanas también los comenta con detalle Borrow (1970: 517, 534-535). 
Figura 4. Portada de la Historia verdadera de la Virgen Dolorosa. [BarceIona], 1837. Fuente: AHN.

Estado 5502, exp. 59.

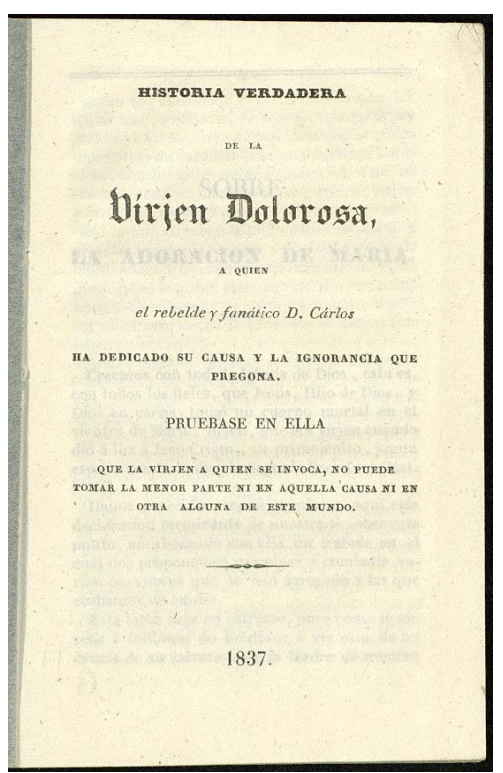

finalidad de estos textos era, como informaba Bergnes a Sebastián Hernández en una carta del 6 de marzo de 1838 , retenida por las autoridades e incorporada al expediente, cubrir los gastos de impresión y hacer frente a los de traducción de los otros tratados que se proponía mandar imprimir. ${ }^{11}$

El cuarto impreso detenido fue la Historia verdadera de la Virgen Dolorosa (1837) (Figura 4). Este folleto llevaba el siguiente provocativo subtítulo: “a quien el rebelde y fanático D. Carlos ha dedicado su causa y la ignorancia que pregona", en clara alusión a la apropiación de la religión como causa política del carlismo, aunque el texto seguía indicando que "pruebase en ella que la Virgen a quien se invoca, no puede tomar la menor parte ni en aquella causa ni en otra alguna de este mundo". El ataque al carlismo resulta interesante ya que coincide con el interés por ganar voluntades entre los sectores liberales que Graydon mostraría en sus viajes y contactos. El contraste con las opiniones publicadas en los diarios carlistas y los medios publicitarios ultracatólicos debió resultar evidente para los lectores (Corrales Burjalés, 2014). Un clero católico muy diversificado, pero que, en opinión de un librero sevillano, en conversación con Borrow, no leía "más que periódicos y los toman sólo por la esperanza de saber que su amigo don Carlos está ya reinstalado en Madrid" (Borrow, 1970: 525). Este librito con la Historia verdadera de la Virgen fue editado en 1837 cuando se estaba preparando en el taller de Bergnes Lo Nou Testament y la Biblia.

\section{La labor de los agentes bíblicos británicos en España, un asunto de Estado}

La labor de Borrow y Graydon se interrumpió a raíz de la enorme ola de oposición que provocó el anuncio publicitario que el irlandés hizo publicar en la prensa malagueña y el descubrimiento simultáneo de la distribución de folletos en los primeros meses de 1838 .

Los testimonios de las autoridades locales reflejan la notable repercusión a raíz de la petición del Cabildo catedralicio de Málaga al obispo reclamando "reparar el escándalo dado y contener la licencia de la prensa" al considerar el artículo de Graydon "ofensivo 
a la Religión, a la verdad, al clero y a la Nación española" (Mateo Avilés, 1986: 25-26). El obispo Valentín Ortigosa, de talante liberal, que en otros muchos asuntos había resistido al clero ultramontano, cedió para evitar acusaciones de colaboracionismo con el protestantismo, y se inició un procedimiento civil, remitiendo el asunto a las autoridades, sin que diversas intervenciones como la del cónsul inglés malagueño, William Penrose Mark, pudieran impedir que Graydon fuera censurado públicamente por la fiscalía general eclesiástica por anunciar "falsamente como biblia entera" ya que faltan "siete libros canónicos que son precisamente los que no reconocen los protestantes". ${ }^{12}$

La censura del obispo electo de Málaga al anuncio de Graydon encontró su eco en la prensa de la corte madrileña y Borrow, que ya estaba en la cuerda floja, se vio implicado. La pertenencia de ambos a la SBBE sugería una estrategia única, aunque en realidad nunca había habido una identificación total entre ambos. La situación de Graydon y Borrow empeoró cuando llegó el eco de una noticia publicada en el periódico La Verdad (17 de mayo de 1838) en la que se afirmaba que los agentes bíblicos habían distribuido en Murcia miles de ejemplares de los cuatro folletos contra el catolicismo (Barrass, 1968: 336). Graydon y Borrow apelaron al embajador británico Villiers, que planteó la protección de los súbditos británicos como un conflicto diplomático de alto nivel al subrayar que, si no se daba una respuesta satisfactoria a la situación de Graydon y Borrow, las relaciones diplomáticas entre ambos países deberían necesariamente revisarse. Aquí, para entender bien la fuerza del argumento del embajador, es necesario recordar que, por el Tratado de la Cuádruple Alianza de 1834, Inglaterra estaba siendo una aliada esencial en la primera guerra carlista (1833-1840), en apoyo de Isabel II. Asimismo, el ministro de Estado en aquel momento era el conde de Ofalia, un moderado que estaba recibiendo enormes presiones de los sectores más conservadores, que lo tachaban de traidor por demasiado tolerante (Nieto, 1996). Fue ministro entre noviembre de 1837 y agosto de 1838 . La sospecha sobre Ofalia ya tenía trayectoria puesto que había sido embajador español en Londres, de 1827 a 1832, en contacto con los círculos liberales españoles en el exilio.

El acuerdo que logró el embajador Villiers fue la liberación de los encarcelados sin que se les abriera proceso formal, debiendo abandonar su actividad como agentes de la SBBE en España. Sus actividades quedaron totalmente bloqueadas por la Real Orden del 19 de mayo de 1838: se prohibía la venta, entrada, impresión y circulación en España de las biblias sin notas ni apócrifos. Era una prohibición taxativa de las actividades de las sociedades bíblicas. Se les invitó amablemente a salir del país. Graydon se fue, temporalmente, a Francia. Se les permitió recuperar todas las ediciones de la Sociedad Bíblica y sacarlas del país. Rule también fue expulsado de Cádiz, donde había creado una escuela y una capilla, como resultado de los decretos que prohibían la difusión religiosa (Orozco Guerrero, 2012).

La tensa relación diplomática se resolvió a favor de España. El 6 de agosto de 1839 el embajador británico escribió a todos los cónsules en España indicándoles que el Ministro de asuntos exteriores Lord Palmerston les comunicaba:

A todos aquellos súbditos británicos quienes, ya sea por medio de la práctica de los sermones o la distribución de libros que puedan atacar a la Iglesia católica española, que serán responsables de sus actos ante la justicia de este país, la cual, con toda probabilidad, les condenará a la pena de prisión o a la expulsión del país; y, del mismo modo, la embajada de Su Majestad británica en Madrid no podrá hacerse cargo de su defensa en los casos de violación clara de las leyes españolas (Giménez Cruz, 1991: 373).

El gobierno español, por su parte, ordenó en 1838 y 1839, que los ejemplares de las biblias existentes salieran de España procurando no hacer más "ruido diplomático".
12. Boletin Oficial literatio, industrial y mercantil de la Provincia de Málaga, 26 de abril de 1838 , núm. 1418 . 
13. Archivo Histórico Provincial de Cádiz, Estado. Gobierno Civil de Cádiz. Sección Imprenta y Prensa. Caja 114. Exp. 55. Agradecemos la referencia a Santiago Saborido, que nos facilitó el documento.
El consulado británico de Cádiz, el 13 de agosto de 1839, dio un recibí al Jefe Político de un "paquetito conteniendo 66 exemplares de la versión del Nuevo Testamento hecha por el P. Scio, y del Evangelio de San Lucas en gitano pertenecientes al súbdito inglés Don Jorge Borrow para enviarlos a Londres", libros que fueron remitidos a Cádiz por el Gobernador Civil de la capital hispalense para que desde allí se embarcasen a Londres. ${ }^{13}$

A pesar de la orden de abandonar el país, Graydon y Borrow intentaron seguir sus actividades. Graydon todavía volvió, de abril a julio de 1839 y de noviembre de 1840 a finales de enero de 1841, a Barcelona, Valencia y Murcia para visitar sus depósitos. El 24 de enero de 1841 un anuncio publicado en El Constitucional de Barcelona informaba de la venta de los restos editoriales dejados por Graydon y no repartidos:

El caballero inglés, que por la sociedad bíblica británica y estrangera de Londres se encargó de imprimir y circular las sagradas Escrituras en la ciudad de Barcelona, y en las provincias españolas del litoral del Mediterráneo, durante los años 1835, 36, 37 y 38 , tiene la satisfacción de volver a poner en conocimiento de esta ciudad y la antigua provincia de Cataluña, que todavía hay existentes algunos ejemplares de la Biblia y nuevo Testamento, que venderá al precio de coste y costas, esto es, a 25 reales la Biblia y a 10 el nuevo Testamento; la primera en castellano y el segundo en catalán, todo impreso y encuadernado en esta ciudad (Fuente, 1842: 212-213).

El 10 de junio de 1841 Graydon volvía a publicitar en el mismo periódico un artículo y una carta explicando las dificultades que se encontraban los que deseaban distribuir los libros editados por Bergnes, recordando la importancia de la libertad y la tolerancia religiosa para adquirir una plena ciudadanía (Roca Vernet, 2018). Descubierto por las autoridades, a Graydon se le indicó con claridad y firmeza que debía abandonar el país. La aventura de estos colportores había acabado.

Borrow culpó a Graydon del fracaso de su misión en La Biblia en España (Giménez Cruz, 1997: 64). Lo presentó casi como un fanático que, en el verano de 1837, estando en Valencia, se lanzó por las calles de la ciudad gritando que Cristo volvería pronto y llamando a la conversión, mientras las biblias permanecían en un hostal al que solo ociosos y curiosos se acercaban para oír frases incoherentes contra la Iglesia de Roma y la Gran Babilonia (Barrass, 1968: 299). Tanto esta autora como Jackson (2000) han subrayado que Borrow lanzó estas apreciaciones de manera interesada, para disculpar sus propios errores o falta de dedicación. La valoración de Borrow en una de las cartas de Luis de Usoz a Benjamin B. Wiffen en 1843 es sintomática: "en mi concepto la conducta y trabajos de Borrow en España podrían haber sido mejores y más ventajosos de lo que fueron a la causa de la propagación del Evangelio" (Vilar Ramírez y Vilar García, 2010: 117). De hecho, Borrow fue desautorizado por la Sociedad Bíblica y Graydon mantuvo su buena opinión en Londres. Más bien, Barras se muestra comprensiva con la defensa que hizo Graydon de su labor. El agente justificaba el tono anti-papal y más beligerante de sus anuncios, a partir de su estancia en Valencia, como una estrategia para definir mejor su propio perfil público. Tras el rechazo abierto que había encontrado, Graydon acentuó este aspecto para conectar mejor con el anticlericalismo y distanciarse de los carlistas. Él mismo explicaba cómo en algunas ciudades como Murcia cuando lo veían tan celoso de la religión y la Biblia algunos lo consideraban carlista (Barrass, 1968: 340).

Graydon y Borrow abandonaron España pero el debate sobre el protestantismo y la libertad de cultos se profundizó en las décadas siguientes. Los folletos protestantes continuaron circulando repartidos por viajeros, marineros y otros personajes de paso. El clero activó una justificación y una renovada defensa católica frente a las acciones de los agentes bíblicos y del protestantismo en general. Las publicaciones se sucedieron de manera inmediata, como las que elaboró F. Palomino Domínguez 
en dos textos, la Demostración en que se manifiesta que la fe y la Religión de los protestantes no es la de la Biblia (Cádiz, 1841) y su Refutación de la obra titulada Cristianismo restaurado (Jerez, 1845). También las cartas pastorales como la publicada por el arzobispo granadino Salvador José de los Reyes García de Lara (1856), a cargo de la diócesis desde 1851 hasta 1865 , que informaba con todo lujo de detalles sobre los antídotos (y lecturas que sirvieran de contraveneno) para "dos folletos sin nombre de autor, ni lugar ni año de impresión que se expenden con la mayor baratura en esta capital por cuenta, según se dice, de una sociedad protestante inglesa", en concreto se trataba de Sobre la libertad de culto y otro folleto titulado Diálogo expositivo de la oración dominical.

Sin duda, uno de los autores más destacados fue Vicente de la Fuente, rector del colegio complutense de Málaga entre 1838 y 1842, quien este último año publicó las Observaciones sobre el protestantismo (Madrid, 1842) a las que siguieron varias publicaciones del mismo tenor en los años siguientes (Fuente, 1842). También Jaume Balmes contribuyó a construir el discurso contra el protestantismo con su muy editada obra El protestantismo comparado con el catolicismo en sus relaciones con la civilización europea (1844), dirigida a desprestigiar y desmontar cualquier discurso favorable a la modernidad del protestantismo en todos los ámbitos.

Y mientras Jaume Balmes y Vicente de la Fuente publicaban sus duras diatribas contra las Biblias "adulteradas" y el protestantismo, Bergnes de las Casas insistía en su impresión y distribución en Barcelona. El compromiso de Bergnes con la difusión de la Biblia era anterior a su contacto con Graydon e intentó, sin éxito, prolongarlo después de su marcha. El 5 de diciembre de 1840 Bergnes solicitó imprimir y distribuir la Biblia y el Nuevo Testamento. Sin notas. La carta es magnífica. En primer lugar, exponía los antecedentes, como impresor, de su relación con la Sociedad Bíblica y el perjuicio que había sufrido por la aplicación de la Real Orden de 19 de mayo de 1838; también, que esa Real Orden, que atribuía al ministro Ofalia, en realidad no había derivado en ningún proceso judicial en el ámbito de las leyes de imprenta y por lo tanto, argumentaba, estaba su petición era perfectamente legal:

Por cuenta de la Sociedad Bíblica Británica y Extranjera de Londres imprimí, en 1836 y 1837, tres ediciones de las Sagradas Escrituras en lengua castellana y catalana. Durante la impresión de dichas ediciones ni en dos años y medio después, no hubo oposición a que se anunciasen y vendiesen públicamente la Biblia y el Nuevo Testamento en esta ciudad y en otros puntos de la provincia y de España, antes al contrario, la obra mereció la aprobación del Exmo Sr. Capitán General Mina, que lo era a la sazón de Cataluña, y ninguna autoridad civil ni eclesiástica en esta ciudad opuso el menor obstáculo a su libre venta y circulación.

Empero esta tolerancia cesó en el momento de encargarse de la administración del reino el ministro Ofalia, quien envió una orden a las jefaturas políticas del reino para embargar todas las Biblias que dicha sociedad estaba circulando en España. De resultas de esta real orden vino a mi casa imprenta un canónigo, delegado por este Sr. Obispo, acompañado de un alcalde constitucional y sus dependientes, para embargar los ejemplares que de dicha obra hubiese en casa. Con efecto: hallaron diecinueve y se los llevaron. Con esta resolución arbitraria del gobierno quedó sin efecto la contrata que yo iba a firmar con dicha Sociedad para la impresión de otros diez mil ejemplares, privándome por consiguiente a mí y a mis operarios del beneficio que aquella impresión nos aseguraba. Bien se deja entender que en todo el tiempo que ha mediado desde entonces no ha habido arbitrio para reclamar contra la infracción de la Constitución, que terminantemente previene que todo delito de imprenta sea juzgado por el Jurado. ${ }^{14}$ 
La llegada al poder de los progresistas, con Espartero a la cabeza a finales de 1840, había hecho albergar nuevas esperanzas a la SBBE que, según Bergnes, estaba dispuesta a encargarle 21.000 ejemplares de la Biblia, aunque, antes de consolidar el encargo pedía garantías legales para su distribución. Bergnes informaba de que, para pulsar el nivel de la posible demanda, había insertado un anuncio en el periódico $E l$ Constitucional, con fecha 15 de noviembre de 1838 (que adjuntaba), afirmando que Graydon había vuelto (aunque esto no era cierto) y retomaba la venta de biblias. Por supuesto, el anuncio despertó las quejas inmediatas de la jerarquía eclesiástica, pidiendo el cumplimiento de la Real Orden del ministro Ofalia.

Las esperanzas abiertas por los progresistas debían concretarse en acciones políticas y jurídicas concretas en beneficio de la difusión de la Biblia, instrumento de regeneración social y política, necesario para la conquista de la libertad, frente a la "fatal preponderancia de Roma". Bergnes señalaba la inconstitucionalidad de la real orden de abril de 1838 en el marco de la Constitución de 1837:

Hallándose ya el asunto en tal estado me tomo la libertad de someter a la recta consideración de $\mathrm{V}$. E. las reflexiones siguientes:

¿La real orden en que se funda el Obispo está arreglada a nuestra Constitución?

¿No debía el Jurado, y no más que el Jurado, entender en el fallo de este asunto? No habiendo mediado esta formalidad imprescindible, única que expresa la opinión pública, ¿no debe considerarse nula la dicha real orden, como ya se tienen por tales otras igualmente opuestas al espíritu y letra de nuestra Constitución?

Los hombres verdaderamente liberales, esto es, los que entienden que la Biblia diseminada por el pueblo es lo que más conduce para ir socavando paulatinamente la fatal preponderancia de Roma y sus agentes, destruyendo la superstición y obligando al clero a observar una conducta más arreglada al Evangelio, están deseando que cunda sin estorbo por todas las clases de la nación. Y si tan cierto es esto, ¿por qué no se ha de consentir que se haga al país un bien de tanta trascendencia? Casi todas las autoridades desean que se haga, pero ataja sus buenos deseos la real orden ya citada del ministerio Ofalia.

Los beneficios de la empresa que proponía redundarían en favor de todas las industrias vinculadas al libro:

Y concretando ahora el punto a mis intereses personales, solo diré a V. E. que si no se pone impedimento a la circulación de la Biblia, tengo por asegurado para años y más años trabajo constante para una docena de prensas. Una docena de prensas necesitan veinte y cuatro prensistas, treinta cajistas, dos correctores y ochenta encuadernadores: no hablo de los fabricantes de papel, pues esta materia ocuparía a una multitud de operarios; todo en beneficio del país. ¿Y no es de lamentar que por no ser tolerante nuestro gobierno como lo son los de Francia, Inglaterra, Béljica, Estados Unidos, Suiza y el vecino de Portugal, únicos países libres, se nos defraude de este beneficio a mí, a mis dependientes y familia?

Para finalizar, Bergnés subrayaba que la circulación del texto bíblico al modo protestante redundaría también en un beneficio político para todos los gobiernos progresistas:

Mucho pudiera extenderme, Exmo. Señor, sobre la conveniencia moral y política de permitir que circule libremente por el reino la Biblia, tal como la reconoce la Iglesia reformada, esto es, sin notas que tuercen el sentido del texto, y sin los libros apócrifos en que funda Roma sus soñadas prerrogativas. iCuánto bien no hará al país la administración que se manifieste tolerante sobre este punto! Sus resultas son inmensas y no se ocultarán a la penetración de V. E. 
Por ello, afirmaba Bergnés, lo más importante, lo esencial, era hacer circular el texto sagrado entre todas las personas esperando que su semilla fructificara:

Así pues solo pido al gobierno, no ya que proteja la empresa, sino que la deje obrar; y todo su obrar se reduce a imprimir y vender el sagrado texto sin notas ni comentarios, porque la palabra divina no las necesita.

En esencia, decía Bergnés, lo que buscaba era la tolerancia religiosa: "y resumiendo todo mi pensamiento, pido para mi patria la tolerancia religiosa que disfrutan todos los países libres de este y del Nuevo Mundo". ${ }^{15}$ Una nota al margen, con fecha 13 de enero de 1841, nos ofrece la respuesta que, quizá, ni siquiera llegó a Bergnés: "no acceder a que se haga declaración alguna sobre el particular por no necesitarlo el estado de nuestra legislación vigente". ${ }^{16}$

\section{Balance}

Probablemente el impacto real de las actividades de Borrow y Graydon fue mucho menor a sus expectativas en cuanto al alcance de la distribución de biblias por todo el territorio español. Contaron con el apoyo de políticos e intelectuales liberales, algunos de los cuales habían pasado por el exilio en el Reino Unido y mantenían lazos de amistad e intereses comunes. Ha sido bien estudiado este tema especialmente para el mundo británico. También el clero liberal, influenciados en algunos casos por el jansenismo, se mostró partidario de la difusión de las Escrituras, eso sí, traducidas por autores católicos, y con la ausencia de notas.

Estos apoyos fueron insuficientes para lograr que Borrow y Graydon desarrollaran sus actividades en España de 1835 a 1840. La presión de las elites eclesiásticas fue enorme y se desarrolló en diversos frentes: el adoctrinamiento diocesano mediante cartas pastorales, el debate en la prensa periódica y, por supuesto, la delación, la labor de crítica de cualquier partidario de los protestantes y los escritos ante las autoridades que dieron origen a algunas reacciones políticas y advertencias al cónsul inglés.

Graydon fue un paso más allá en sus objetivos como agente de la SBBE al distribuir folletos protestantes que abiertamente subrayaban las críticas a la Iglesia católica y las diferencias con el protestantismo. Esta decisión lo situó claramente en la ilegalidad, pero, sobre todo, le granjeó una enorme oleada crítica en la que también se incluyó a Borrow. Y se convirtió en un problema político con dimensión diplomática. Todo ello en el marco de los primeros pasos de la construcción del Estado liberal, tensionado profundamente durante la primera guerra carlista, y mientras la Iglesia católica sufría un proceso de desamortización de parte de sus bienes que anuncia la pérdida de su poder si los liberales gobernaban durante mucho tiempo. Las presiones políticas eran muy fuertes. La batalla de la opinión se libró intensamente en la prensa periódica, pero las decisiones de mayor o menor permisividad se tomaron en los despachos ministeriales y las acciones represivas se ejecutaron a través de los gobernadores civiles y los obispos.

Las estrategias de venta utilizadas por los agentes bíblicos revelan un uso de medios sencillos, como la publicidad en la prensa local de cada ciudad y los carteles, destinados a fomentar el consumo con motivo de la llegada del colportor. Graydon necesitaría visitar las ciudades, establecer acuerdos con libreros locales y vender al por menor en fondas y posadas. En este tráfico contó con la ayuda de libreros, y aliados como Bergnes de las Casas que contaba con una notable trayectoria editorial y tenía colegas en varias ciudades del litoral mediterráneo. Graydon también tuvo como colaboradores ocasionales a comisionistas en las fondas en las que residió, y 
logró la complicidad de algunos liberales e incluso algunos párrocos, sin olvidar su interés en difundir folletos como la Historia verdadera de la Virgen Dolorosa (1837) que le mostraban alejado de los ideales carlistas.

Las cifras de venta de Biblias que Graydon va anotando en su correspondencia con la SBBE revelan un interés de los españoles en la lectura de los textos en lenguas vernáculas, en catalán y castellano, motivado por el precio económico y la oportunidad de conseguirlo en circuitos informales, a través de puntos de venta ocasionales y usando a algunos intermediarios. En todo caso fue un volumen de ventas limitado, que en modo alguno pudo lograr un acceso a textos bíblicos de manera generalizada. Con todo, la presencia y actuación de Borrow y Graydon amplió el debate sobre la tolerancia religiosa y la lectura de la Biblia.

Finalmente, los textos impresos protestantes de los años treinta del siglo XIX, editados en el extranjero o en España, tuvieran una difusión limitada. El resultado es un aparente vacío de textos protestantes, una suerte de biblioteca evaporada que no ha dejado apenas poso en las colecciones patrimoniales. En el caso de los folletos protestantes editados por Graydon, probablemente en el taller de Bergnes de las Casas, se recogieron por las autoridades y de ellos apenas hay ejemplares conservados. La aparente inexistencia de ejemplares de estos folletos en las bibliotecas y archivos españoles fue, en gran medida, consecuencia de una combinación de indiferencia, rechazo e ignorancia a la aportación de las iglesias protestantes europeas en el marco del debate religioso. El que apenas se conserven debería hacernos reflexionar sobre el patrimonio reunido, que revela notables ausencias y ofrece una imagen que olvida a numerosos actores de la historia, difícilmente recuperables ante el predominio de los libros de los "otros", que hacen olvidar la diversidad y la riqueza del debate en torno a la libertad religiosa y la tolerancia. 


\section{Q Referencias Bibliográficas}

》Alonso, Gregorio. 2014. La Nación en capilla. Ciudadanía católica y cuestión religiosa en España (1793-1874). Granada: Comares Historia.

» Azaña, Manuel. 1920. Jorge Borrow y la Biblia en España. En La Pluma. Año 1, no. 4 (1 de septiembre de 1920), 170-181.

"Barnosell, Genís. 2012. God and Freedom: Radical Liberalism, Republicanism and Religion in Spain, 1808-1847. En International Review of Social History. Vol. 57, no. 1, 37-59. <doi:10.1017/So020859011000733>

"Barrass, Tine. 1968. The Catalan New Testament and The British and Foreign Bible Society, 1820-1888. Girton: Girton College, Universidad de Cambridge. 2 v. Tesis de doctorado.

»Bastian, Jean-Pierre. 2001. Problemas y métodos para la investigación de los protestantismos ibéricos de los siglos XIX y XX. En Anales de Historia Contemporánea. Vol. 17, 21-34. <https://revistas.um.es/analeshc/article/view/56271 > [Consulta: 19 enero 2021].

»Bedera Bravo, Mario y Ángel de Prado Moura. 2014. Desidencia política y heterodoxia religiosa en la España del primer tercio del siglo XIX: la represión de los tribunales de Inquisición. En Serrano García, R. et al., eds. Discursos y devociones religiosas en la Península Ibérica, 1780-1860: De la crisis del Antiguo Régimen a la consolidación del Liberalismo. Valladolid: Ediciones Universidad de Valladolid. p. 117-140.

»Biblia. 2008. Lo Nou Testament: traducció de Josep Melcior Prat. Transcripció a cura d'Antoni Coll i Casals. Notes de Pere Casanellas i Bassols. Barcelona: Abadia de Montserrat: Associació Bíblica de Catalunya.

»Borrow, George. 1970. La Biblia en España. Madrid: Alianza.

» Botrel, Jean-François. 2008. La 'Biblioteca de Autores Españoles’ (1846-1878), ou la difficile construction d'un panthéon des lettres espagnoles. En Histoire et Civilisation du Livre. Revue Internationale. No. 4, 201-221. <https://revues.droz. org/index.php/HCL/article/view/1973 > [Consulta: 19 enero 2021].

"Browne, George. 1859. The history of the British and Foreign Bible Society: From Its Institution in 1804, to the close of its Jubilee in 1854. London: Bagster | British and Foreign Bible Society

»Caballer Albareda, Gemma. 2020. La caiguda dels murs de la intolerància: les presons i els hospitals de Barcelona vistos per dos quàquers. En Luttikhuizen, Frances, coord. Un dia de fúria. Barcelona, 10 de març de 1820. Barcelona: Publicacions de l'Abadia de Montserrat. p. 77-90.

»Camós, Agustí. 1998. Antoni Bergnes de las Casas (1801-1879), difusor de la cultura científica y del transformismo lamarckista. En Llull. Revista de la Sociedad Española de Historia de las Ciencias y de las Técnicas. Vol. 21, no. 42, 633653. <https://dialnet.unirioja.es/servlet/articulo?codigo=62214 > [Consulta: 19 enero 2021].

"Camós, Agustí. 2013. Disidencia religiosa, humanitarismo y evolución: el caso de Antoni Bergnes de las Casas (1801-1879). En Calvo, Luis; Álvaro Girón y Miguel Ángel Puig-Samper, eds. Naturaleza y laboratorio. Barcelona: CSIC. p. 145-172. 
"Camós, Agustí. 2020. Antoni Bergnes de las Casas i l'assalt al tribunal de la Inquisició de Barcelona l'any 1820. En Luttikhuizen, Frances, coord. Un dia de fúria. Barcelona, 10 de març de 1820. Barcelona: Publicacions de l'Abadia de Montserrat. p. $105-117$.

» Capó i Fuster, Carmen. 1994. Esforços per introduir la lectura de la bíblia a Espanya a principis del s. XIX (1808-1821). El paper de la Societat Bíblica Britànica i Estrangera. En Analecta Sacra Tarraconensia. Vol. 67, no. 2, 287-299. <https://www.raco.cat/index.php/AnalTar/article/view/381819 > [Consulta: 19 enero 2021].

»Capó i Fuster, Carmen. 2020. El paper de la Societat Bíblica Britànica i Estrangera en la revolució liberal (1820-1826). En Luttikhuizen, Frances, coord. Un dia de fúria. Barcelona, 10 de març de 1820. Barcelona: Publicacions de l'Abadia de Montserrat. p. 91-104.

"Cobbett, William. 1850. Nuevas cartas de William Cobbett á los ministros de la Iglesia de Inglaterra é Irlanda, ó sea, Continuacion de la Historia de la Reforma del mismo autor traduccion de Nicolás de Castro Palomino. Seguidas de un Tratado sobre la esterilidad de las misiones protestantes por el Emo. Sr. Wisseman. BarceIona: Librería Religiosa, Impr. de Pablo Riera.

»Collie, Michael. 1982. George Borrow: eccentric. Cambridge: Cambridge University Press.

»Corrales Burjalés, Laura. 2014. L'estampa i la primera guerra carlina a Catalunya (1833-1840). Bellaterra: Universitat Autònoma de Barcelona. Departament d'Art i de Musicologia. 875 p. Tesis de doctorado. <http://hdl.handle. net/10803/285549> [Consulta: 19 enero 2021].

" Eaton, Kent. 2015. Protestant Missionaries in Spain, 1869 1936: "Shall the Papists Prevail?". Lanham: Lexington Books.

》Eguizábal, José Eugenio de. 1879. Apuntes para una historia de la legislación española sobre imprenta desde el año de 1480 al presente 1873. Madrid: Imprenta de la Revista de Legislación. <http://www.cervantesvirtual.com/obra/apuntespara-una-historia-de-la-legislacion-espanola-sobre-imprenta--desde-el-anode-148o-al-presente/ > [Consulta: 19 enero 2021].

» Fradera, Josep M. 1996. Jaume Balmes. Els fonaments racionals d'una política catòlica. Vic: Eumo.

» Fradera, Josep M. 2002. La religió, entre el vell món i el nou. En Barcelona Quaderms d'Història. No. 6, 105-119. <https://www.raco.cat/index.php/BCNQuadernsHistoria/article/view/105322 > [Consulta: 19 enero 2021].

»Fuente, Vicente de la. 1842. Observaciones sobre el protestantismo discurso compuesto para leerlo en el Consejo del Rey de Francia por un Ministro amante de su patria traducido libremente del francés por Vicente de la Fuente. Madrid: Imprenta de Don Eusebio Aguado.

» Garcia i Espuche, Albert y Manuel Guàrdia i Bassols. 1986. Espai i societat a la Barcelona pre-industrial. Barcelona: La Magrana; Institut Municipal d'Història.

" Ghanime Rodríguez, Albert y David Cao Costoya. 2013. Antoni Giberga i el liberalisme progressista a Barcelona durant la minoria d'edat d'Isabel II. Barcelona: Arxiu Històric de la Ciutat de Barcelona.

» Gili, Joan. 1943. A l'entorn del Nou Testament en Català imprès a Londres l'any 1832. En Butlletin of Spanish Studies. Vol. 20, 243-246. 
» Giménez Cruz, Antonio. 1987. James N. Graydon, comisionado de la Sociedad Bíblica de Londres: controversias sobre su actuación en España (1835-1840). En Hispania: Revista española de historia. Vol. 47, no. 165, 225-250.

" Giménez Cruz, Antonio. 1991. La prensa española de la época y George Borrow. En Anales del Instituto de Estudios Madrileños. Vol. 30, 361-380.

» Giménez Cruz, Antonio. 1997. ¡Cosas de los ingleses!: la España vivida y soñada en la correspondencia entre George Borrow y Richard Ford. Madrid: Complutense.

"Howsam, Leslie. 2004. The Bible Society and the Book Trade. En Batalden, Stephen; Kathleen Cann y John Dean, eds. Sowing the Word: The Cultural Impact of the British and Foreign Bible Society, 1804-2004. Sheffield: Sheffield Phoenix Press. p. 24-37.

» Jackson, Sue. 2004. The Bible in Spain and Gibraltar. En Batalden, Stephen; Kathleen Cann y John Dean, eds. Sowing the Word: The Cultural Impact of the British and Foreign Bible Society, 1804-2004. Sheffield: Sheffield Phoenix Press. p. 305-315.

" Jackson, Susan Irene. 2000. Methodism in Gibraltar and its mission in Spain, 17691842, Durham: Durham University. 287 p. Tesis de doctorado. <http://etheses. dur.ac.uk/4242/ > [Consulta: 19 enero 2021].

" Janué i Miret, Marició. 2004. La crisi del règim isabelí a Barcelona. En Barcelona Quaderns d'Història. No. 10, 235-261. <https://www.raco.cat/index.php/BCNQuadernsHistoria/article/view/105579 > [Consulta: 19 enero 2021].

» Jardí, Enric. 1960. Antoni Puigblanch. Els precedents de la Renaixença. Barcelona: Aedos.

»La Parra, Emilio y María Ángeles Casado. 2013. La Inquisición en España. Agonía y abolición. Madrid: Los Libros de la Catarata.

»Llorens, Vicente. 1968. Liberales y románticos. Una emigración española en Inglaterra, 1823-1834. Madrid: Castalia.

» Martí Gilabert, Francisco. 1975. La abolición de la Inquisición en España. Pamplona: Ediciones de la Universidad de Navarra.

" Mateo Avilés, Elías de. 1986. Masonería, protestantismo, librepensamiento y otras heterodoxias en la Málaga del siglo XIX. Málaga: Diputación Provincial de Málaga.

" Medina Calzada, Sara. 2019. The Felon King: Ferdinand VII in British Print Culture (1814-1833). En Bulletin of Spanish Studies. Vol.96, no. 6, 951-973.

" Melchor, Vincent de. 2000. Una traducció en català valencià dels evangelis, a Oxford, del segle XVIII. En Quaderns. Revista de traducció. No. 5, 55-68.

" Mestre Sanchis, Antonio. 2017. Biblia e llustración en la crítica de la religiosidad barroca. En Cuadernos de estudios del siglo XVIII. No. 27, 139-166. <https://doi. org/10.17811/cesxviii.27.2017.139-166>

» Moliner i Prada, Antoni. 2016. En torno a la Revolución Liberal y la Iglesia española del siglo XIX. En Ler História. 69, 31-50. <https://doi.org/10.400o/lerhistoria.2475>

»Moliner i Prada, Antoni. 2018. La secularización en Cataluña en los informes episcopales (1800-1867). En Hispania sacra. Vol. 70, no. 141, 305-319. <https:// doi.org/10.3989/hs.2018.023> 
» Nieto, Alejandro. 1996. Los primeros pasos del Estado constitucional: historia administrativa de la Regencia de María Cristina de Borbón. Barcelona: Ariel.

» Olives Canals, Santiago. 1947. Bergnes de las Casas, helenista y editor, 1801-1879. Barcelona: CSIC.

» Orozco Guerrero, Antonio. 2012. La aplicación de la libertad religiosa en Cádiz durante el Sexenio Democrático en relación con los protestantes (1868-1874). En Espacio, tiempo y Forma, Serie V, Historia Contemporánea. No. 24, 267-290. $<$ https://doi.org/10.5944/etfv.24.2012.10267 >

"Owen, John. 1817. The history of the origin and first ten years of the British and Foreign Bible Society. New York.

»Reyes García de Lara, Salvador José. 1856. Carta pastoral del Excmo. é Illmo. Sr. Don Salvador Josef de Reyes García de Lara, Arzobispo de esta diócesis, para condenar dos folletos protestantes, y prevenir a sus diocesanos contra las asechanzas del protestantismo y de otros enemigos de la Iglesia. Granada: Imprenta y Librería de D. Gerónimo Alonso.

» Roca Vernet, Jordi. 2011. La Barcelona revolucionària i liberal: exaltats, milicians i conspiradors. Barcelona: Fundació Noguera.

» Roca Vernet, Jordi. 2018. La llibertat de cultes i la tolerància religiosa a la premsa liberal de Barcelona durant el Trienni Progressista (1840-1843). En Barcelona Quaderns d'Història. No. 25, 111-122. <https://www.raco.cat/index.php/BCNQuadernsHistoria/article/view/352211> [Consulta: 19 enero 2021].

» Roca Vernet, Jordi y Núria Miquel Magrinyà. 2021. La bullanga de Barcelona: 25 de juliol de 1835. Barcelona: Rosa dels Vents.

" Romea Castro, Celia. 2016. Barcelona romántica y revolucionaria: una imagen literaria de la ciudad (1833-1843). $2^{\underline{a}}$ ed. Barcelona: Edicions de la Universitat de Barcelona.

"Santiño, Santiago. 2018. Pascual de Gayangos. Erudición y cosmopolitismo en la España del siglo XIX. Pamplona: Urgoiti Editores.

»Thion Soriano-Molla, Dolores. 2013. Antonio Bergnes de las Casas, un editor para todos. De los primeros pasos en el gremio a El Museo de Familias (Indices). En Anales de Literatura Española. No. 25, 341-382. <https://doi.org/10.14198/ ALEUA.2013.25.16>

"Thomson, James. 1853. Spain, its position and evangelization: also, Protestant religious liberty abroad. London: Partridge and Oakey.

»Torres Amat, Fèlix. 1838. Sobre las versiones de la Biblia sin notas. Reflexiones que hice presentes al supremo gobierno y que añadidas algunas palabras se extractaron después de la Gaceta del 5 de este mes y en otros periódicos. Madrid: Imprenta que fue de Fuentenebro, a cargo de Alejandro Gomez. <https://bpa.orex.es/ bib/66748> [Consulta: 19 enero 2021].

»Vilar García, Mar. 2004. Docentes, traductores e intérpretes de la lengua inglesa en la España del siglo XIX: Juan Calderón, los hermanos Usoz y Pascual de Gayangos. Murcia: Universidad de Murcia.

»Vilar Ramírez, Juan Bautista. 1994. Intolerancia y libertad en la España contemporánea. Los orígenes del protestantismo español actual. Madrid. Istmo.

»Vilar Ramírez, Juan Bautista. 2008. Literatura y disidencia religiosa en España en el siglo XIX: la difusión en el sureste peninsular desde Alicante de libros y folletos protestantes por tripulantes de un buque norteamericano (1857). En 
Cervera Salinas, Vicente y María Dolores Adsuar Fernández, eds. Alma América: in honorem Victorino Polo. Murcia: Universidad de Murcia. Vol. 2, p. 448-46o.

"Vilar Ramírez, Juan Bautista y Mar Vilar García. 2010. El primer hispanismo británico en la formación y contenidos de la más importante biblioteca española de libros prohibidos: correspondencia inédita de Luis de Usoz con Benjamin Wiffen (1840-1850). Sevilla: Ed. MAD/ Eds. CIMPE.

»Zaro, Juan Jesús. 2015. Traducción y propaganda religiosa: Gibraltar y la labor traductora de William Harris Rule. En Quaderns. Revista de Traducció. No. 22, 135-148. < https://www.raco.cat/index.php/QuadernsTraduccio/article/ view/294260 [Consulta: 19 enero 2021].

"Zazo Esteban, Alberto. 2015. La «literatura» de la Segunda Reforma española. Valladolid: Universidad de Valladolid. Tesis de doctorado. <http://uvadoc.uva. es/handle/10324/16326> [Consulta: 19 enero 2021]. 
